\title{
Analysis of differences in subjective health status according to characteristics of hospitalized cancer patients
}

\author{
Ji-Youn Kim', Eun-Surk Yi,* \\ 'Exercise Rehabilitation Convergence Institute, Gachon University, Incheon, Korea \\ 2Department of Exercise Rehabilitation \& Welfare, College of Health Science, Gachon University, Incheon, Korea
}

This study is intended to analyze differences in the self-rated health of patients according to the characteristics of hospitalized cancer patients. To this end, this study analyzed the differences in self-rated health according to cancer diagnosis type, cancer stage and adjunctive treatment and analyzed the recognition of difficulties in physical activities during hospitalization. A questionnaire survey was conducted among data of 162 hospitalized cancer patients. For the self-rated health of cancer patients according to diagnosis type, it was lower in the gastric cancer group than in the thyroid cancer group and the breast cancer group. For self-rated health according to cancer stage, it was higher in the order of the stage 3 group, stage 2 group and stage 1 group. For the self-rated health of patients receiving adjunctive treat- ment, it was the lowest in the chemotherapy+radiotherapy group. And for personal constraints according to cancer stage in the category of "physical," it was higher in the stage 3 group than in the stage 1 group. For hospital environment restrictions according to cancer stage in the category of "tool," it was higher in the stage 1 group than in the stage 3 group. In conclusion, personal constraints on the physical activities of cancer patients appear to be due to fatigue and a lack of motivation, but medical services that influence motivation are critical to individual and continued care strategies for the patients.

Keywords: Hospitalized cancer patients, Self-rated health, Characteristics, Personal constraints, Hospital environment, Physical activity

\section{INTRODUCTION}

In recent years, with the early diagnosis of cancer, development of therapeutic technology, and changes in life and recognition, the survival rate of cancer patients has been steadily increasing. The 5 -year relative survival rate of cancer patients over the last 5 years (2010-2014) was 70.3\%, a $16.4 \%$ improvement in comparison with 53.9\% in 2001-2005 (Ministry of Health and Welfare, 2018). As such, cancer is being recognized as a chronic disease due to the increasing survival rate, increasing the importance and necessity of continuous care for cancer survivors (Parsaie et al., 2000). Cancer occurrence is closely related to lifestyle, so it is very important to maintain a proper lifestyle after the treatment process. And chemotherapy and radiotherapy during the treatment pro- cess, personal genetic factors, exposure to the environment, lifestyle, etc. may affect cancer recurrence and secondary cancer development. Therefore, it is critical to change lifestyle for the improvement of cancer survival and cure and for the prevention of the progression or recurrence of cancer as well as the risk of cancer development.

Lifestyle is defined as the daily habits and behaviors of people while living (Shrestha and Ghimire, 2012), and lifestyles related to health are very diverse. Among them, physical activity is a means of reducing side effects for cancer patients (Andersen et al., 2006), and many studies have been conducted on the positive effect of exercise on psychological variables, quality of life and fatigue in cancer patients, and on the improvement of physical function, body composition, strength, immune function, etc.
${ }^{\star}$ Corresponding author: Eun-Surk Yi iD https://orcid.org/0000-0002-9370-5231 Department of Exercise Rehabilitation \& Welfare, College of Health Science, Gachon University, 191 Hambangmoe-ro, Yeonsu-gu, Incheon 21936, Korea Tel: +82-32-820-4442, Fax: +82-32-820-4442, E-mail: Yies@gachon.ac.kr Received: July 18, 2018 / Accepted: August 13, 2018
This is an Open Access article distributed under the terms of the Creative Commons Attribution Non-Commercial License (http://creativecommons.org/licenses/by-nc/4.0/) which permits unrestricted non-commercial use, distribution, and reproduction in any medium, provided the original work is properly cited. 
(Hennessy et al., 2005; Midtgaard et al., 2009). However, most cancer patients do not resume physical activity to the extent that they did prior to cancer diagnosis, even if they are able to do so, and they do not increase their participation in exercise or physical activity after treatment (Pinto et al., 2002).

It is reported that cancer patients experience pain, chronic discomfort, and fatigue, and psychiatric problems such as loss of self-esteem, anxiety, and depression (Hinz et al., 2010; Jacobsen et al., 2010). Chronic fatigue, anxiety, depression, etc. act as constraints on the patient's participation in physical activities (Eng et al., 2018), which not only degrades quality of life but also has a critical impact on survival and recovery. Nevertheless, it has been reported that the longer the time after cancer diagnosis, the lower the practice rate of healthy behavior, and that the lifestyle of cancer survivors degenerates rather than improves (Li et al., 2009).

Therefore, it is very important that education and physical activity for cancer patients is conducted during the hospitalization period because cancer patients contact medical staff more often during the hospitalization period. In particular, Young-McCaughan and Arzola (2007) reported that it is important that nurses and medical staff make sure that patients and their families recognize the value and effectiveness of safe exercise management and continued exercise as well as suggest exercises to patients as part of treatment. This emphasizes the importance of educating patients and families about the value and effectiveness of physical activity, not just exercise prescription (Suhonen, 2018).

In fact, not many studies have been conducted on the physical activity of cancer patients, the analysis of differences in health status according to cancer diagnosis type and stage, and difficulties in physical activity.

Therefore, this study was intended to investigate and improve constraints on self-rated health and the physical activity of cancer patients during the hospitalization period and to provide the basic data required to seek ways to recognize the importance of physical activity according to the characteristics of cancer patients during hospitalization by improving those constraints.

\section{MATERIALS AND METHODS}

\section{Study subjects}

In this study, adult male and female hospitalized cancer patients (aged 20+) in the Gyeonggi area were selected as the population. Using the purposive sampling method, 200 hospitalized cancer patients were selected. The questionnaire survey was conducted from January 2018 to March 2018. Data from 162 patients were
Table 1. General and disease-related characteristics of subjects

\begin{tabular}{|c|c|}
\hline Variable & №. $(\%)$ \\
\hline \multicolumn{2}{|l|}{ Gender } \\
\hline Male & 88 (54.32) \\
\hline Female & 74 (45.68) \\
\hline \multicolumn{2}{|l|}{ Education } \\
\hline $20-30 s$ & 39 (24.07) \\
\hline $40-50 \mathrm{~s}$ & 63 (38.89) \\
\hline$\geq 60 \mathrm{~s}$ & $60(37.04)$ \\
\hline \multicolumn{2}{|l|}{ Education } \\
\hline High school & $113(69.75)$ \\
\hline College & $49(30.25)$ \\
\hline \multicolumn{2}{|c|}{ Average household income (monthly) } \\
\hline$<$ KRW 2 million & 41 (25.31) \\
\hline KRW 2-3 million & 54 (33.33) \\
\hline KRW 3-4 million & $35(21.61)$ \\
\hline > KRW 4 million & 32 (19.75) \\
\hline \multicolumn{2}{|l|}{ Marriage } \\
\hline Married & $119(73.46)$ \\
\hline Unmarried & $37(22.84)$ \\
\hline Others & $6(3.7)$ \\
\hline \multicolumn{2}{|l|}{ Vocation } \\
\hline Office worker & $37(22.84)$ \\
\hline Production/Labor & $44(27.16)$ \\
\hline Service/self-employed & $33(20.37)$ \\
\hline Housewife & 31 (19.14) \\
\hline Others & $17(10.49)$ \\
\hline \multicolumn{2}{|l|}{ Experience of exercise } \\
\hline Yes & $65(40.12)$ \\
\hline No & $97(59.88)$ \\
\hline \multicolumn{2}{|l|}{ Diagnosis type } \\
\hline Thyroid cancer & 32 (19.75) \\
\hline Breast cancer & $46(28.4)$ \\
\hline Gastric cancer & 68 (41.97) \\
\hline Others & $16(9.88)$ \\
\hline \multicolumn{2}{|l|}{ Hospitalization period (day) } \\
\hline $1-4$ & 48 (29.63) \\
\hline $5-7$ & $79(48.77)$ \\
\hline$>7$ & $35(21.6)$ \\
\hline \multicolumn{2}{|l|}{ Cancer stage } \\
\hline 1 & 48 (29.63) \\
\hline 2 & 32 (19.75) \\
\hline 3 & $66(40.74)$ \\
\hline Others & $16(9.88)$ \\
\hline \multicolumn{2}{|l|}{ Adjunctive treatment } \\
\hline No & $82(50.62)$ \\
\hline Yes & 80 (49.38) \\
\hline Chemotherapy & $37(46.25)$ \\
\hline Radiotherapy & $20(25)$ \\
\hline Chemotherapy+radiotherapy & $23(28.75)$ \\
\hline
\end{tabular}


finally used for analysis, except for data from 38 patients which were judged to be incomplete or insincere. The general characteristics of the subjects are listed in Table 1 below.

\section{Survey tool}

In this study, a questionnaire was used as a tool to collect data for the analysis of the differences in self-rated health according to the characteristics of cancer patients. For self-rated heath, we used a five-level EuroQol five-dimensional questionnaire (EQ-5D-5L), which is widely used in the study of health-related quality of life (HRQoL) (Brooks, 1996; Korea Centers for Disease Control and Prevention, 2017; Tajima et al., 2010). It is based on 100-point scale, and the higher the score, the healthier the patient is. For personal constraints and hospital environment constraints, the questionnaire used in the study by Chang and Yi (2018) was used after supplementation and modification. After a preliminary questionnaire with 50 hospitalized patients, the final questionnaire was composed of a total of 39 questions (seven questions about background variables, four questions about disease characteristics, four questions about participation in exercise, 13 questions about personal constraints, eight questions about hospital environmental constraints, and one question about self-rated health) after excluding questions with a factor load of 0.4 or less. The contents of the questionnaire were modified and supplemented using easy-to-understand terms. And the final questionnaire was reviewed by three professors (nursing science, physiotherapy, and exercise rehabilitation). Table 2 shows the composition index and contents of the questionnaire used in this study.

\section{Reliability and validity of questionnaire}

For the reliability and validity of the questionnaire, $\mathrm{PhDs}$ in nursing science, physiotherapy, sports rehabilitation, medicine, sports sociology, and exercise physiology reviewed and commented on it in an experts meeting. Based on the collected data, the validity was verified using confirmatory factor analysis. In self-rated health with a 100-point scale, a higher score indicates a healthier status. As a result of factor analysis of 13 questions about personal constraints, three factors were derived. Among them, the factor load of physical constraint was $0.618-0.806$, the factor load of cognitive psychological constraint was $0.593-0.748$ and the factor load of sociocultural constraint was $0.646-0.796$, respectively, indicating that the measurements were made validly.

As a result of factor analysis of eight questions about hospital environment constraints, four factors were derived. Among them, the factor load of program was $0.569-0.808$, factor load of space
Table 2. Questionnaire composition index

\begin{tabular}{lc}
\hline Composition & No. of questions \\
\hline General characteristics & 7 \\
Gender & \\
Age & \\
Education & \\
Experience of exercise & \\
Average household income (monthly) & \\
Income & \\
Marriage & \\
Disease characteristics & \\
Diagnosis name & \\
Hospitalization period & \\
Stage & \\
Treatment method & \\
Self-rated health & \\
Perceived health status on 100-point scale & \\
Participation in exercise & \\
Type & \\
Frequency & \\
Period & \\
Intensity & \\
Individual constraints & \\
Physical & \\
Sociocultural & \\
Cognitive psychological & \\
Hospital environment constraints & \\
Hospital program & \\
Hospital space & \\
\hline
\end{tabular}

was $0.579-0.806$, the factor load of tool was $0.545-0.792$, and the factor load of service was $0.566-0.792$, indicating that the measurements were made validly. As a result of testing reliability using Cornbach $\alpha$, the reliability of personal constraint was 0.811 and the hospital environment constraint was 0.769 .

\section{Survey procedure and data processing}

To survey the self-rated health according to the characteristics of cancer patients, the researchers and assistant researchers visited the hospitals and requested a questionnaire survey with the prior consent of the officials in the cancer centers in the Gyeonggi area. The purpose of the questionnaire and method of answering it were explained to the survey subjects, who were then asked to fill out the questionnaire by self-administration.

Among the questionnaires collected, unreliable answers, duplicated answers, and missing answers were excluded from the analy- 
sis. Data that were deemed to be reliable were individually coded and processed according to the purpose of analysis using the IBM SPSS version 23.0 (IBM Co., Armonk, NY, USA) statistical program. For the statistical method used in the study, descriptive statistical analysis, $t$-test, and one-way analysis of variance were performed at a significance level of $P<0.05$.

\section{RESULTS}

Table 1 shows the general characteristics of the study subjects. For self-rated health $(F=16.235)$ according to the diagnosis type of cancer patients, it was lower in the gastric cancer (mean $=41.2)$ group than in the thyroid cancer (mean $=46.3)$ group and the breast cancer (mean $=45.1)$ group. This implies that the patients diagnosed with gastric cancer and other cancers evaluate themselves to be less healthy compared to the patients with a relatively short hospitalization period, such as thyroid cancer patients and breast cancer patients (Table 3).

For self-rated health $(F=13.429)$ according to the cancer, it was higher in the order of stage $3($ mean $=23.5)$, stage $2($ mean $=35.5)$,

Table 3. Mean and standard deviation of self-rated health according to cancer characteristics and F-test

\begin{tabular}{|c|c|}
\hline Disease characteristic & Mean \pm SD \\
\hline \multicolumn{2}{|l|}{ Diagnosis type } \\
\hline Thyroid cancer $(\mathrm{n}=32)^{\mathrm{a}}$ & $46.3 \pm 0.98$ \\
\hline Breast cancer $(n=46)^{b}$ & $45.1 \pm 0.93$ \\
\hline Gastric cancer $(n=68)^{c}$ & $41.2 \pm 1.23$ \\
\hline Others $(n=16)^{d}$ & $42.2 \pm 0.96$ \\
\hline F-value & $16.235^{* *}$ \\
\hline Posthoc & $c<a, b$ \\
\hline \multicolumn{2}{|l|}{ Cancer stage } \\
\hline $1(n=48)^{a}$ & $42.5 \pm 0.45$ \\
\hline $2(n=32)^{b}$ & $35.5 \pm 0.40$ \\
\hline $3(n=66)^{c}$ & $23.5 \pm 0.61$ \\
\hline Others $(n=16)^{d}$ & $40.2 \pm 0.42$ \\
\hline F-value & $13.429^{*}$ \\
\hline Posthoc & $c<b<a, d$ \\
\hline \multicolumn{2}{|l|}{ Adjunctive treatment } \\
\hline Chemotherapy $(\mathrm{n}=37)^{a}$ & $51.2 \pm 1.96$ \\
\hline Radiotherapy $(\mathrm{n}=20)^{\mathrm{b}}$ & $45.5 \pm 1.23$ \\
\hline Chemotherapy + radiotherapy $(n=23)^{c}$ & $40.6 \pm 0.96$ \\
\hline F-value & $15.562^{\mathrm{C} *}$ \\
\hline Posthoc & $c<b<a$ \\
\hline
\end{tabular}

$\mathrm{SD}$, standard deviation.

${ }^{*} P<0.05 .{ }^{*} P<0.01$. Post hoc - Statistically significant difference between groups. and stage 1 (mean $=42.5)$. In other words, the more cancer progresses, the more they evaluate themselves unhealthy. For self-rated health $(F=15.562)$ according to adjunctive cancer treatment, it was lower in the chemotherapy+radiotherapy $($ mean $=40.6)$ group than in the chemotherapy (mean = 51.2) group and the radiotherapy (mean $=45.5)$ group. In other words, among the patients diagnosed with cancer, patients treated with multiple therapies evaluate themselves as unhealthy (Table 3).

For personal constraints in the category of "physical" according to cancer stage, it was higher in the stage 3 (mean =4.09) group than the stage 1 (mean $=3.88$ ) group. In other words, the more the cancer progresses, the more constraints on the participation in exercise there are. In the category of "sociocultural" ( $F=4.211)$, it was higher in the stage 3 (mean=4.13) group than in the stage 1 $($ mean $=4.01)$ group. In other words, the more the cancer progresses, the higher the sociocultural constraint on exercise (Table 4).

For hospital environment constraints in the category of "tool" $(F=4.033)$ according to cancer stage, it was higher in the stage 1 $($ mean $=4.15)$ group than in the stage $3($ mean $=4.00)$ group. In other words, the patients would like to participate in physical ac-

Table 4. Mean and standard deviation of personal constraints according to cancer stage and $F$-test

\begin{tabular}{|c|c|c|c|c|c|c|}
\hline \multirow{2}{*}{$\begin{array}{l}\text { Cancer } \\
\text { stage }\end{array}$} & \multicolumn{2}{|c|}{ Physical } & \multicolumn{2}{|c|}{ Cognitive psychological } & \multicolumn{2}{|c|}{ Sociocultural } \\
\hline & Mean \pm SD & No. & Mean $\pm S D$ & No. & Mean \pm SD & No. \\
\hline 1 & $3.88 \pm 0.51$ & 48 & $4.12 \pm 0.96$ & 48 & $4.01 \pm 0.96$ & 48 \\
\hline 2 & $4.00 \pm 0.75$ & 32 & $4.09 \pm 0.68$ & 32 & $4.11 \pm 0.86$ & 32 \\
\hline 3 & $4.09 \pm 0.89$ & 66 & $4.08 \pm 0.46$ & 66 & $4.13 \pm 0.56$ & 66 \\
\hline Others & $3.99 \pm 0.56$ & 16 & $4.02 \pm 0.56$ & 16 & $4.09 \pm 0.66$ & 16 \\
\hline F-value & $7.218^{* *}$ & & & & $4.211^{*}$ & \\
\hline Posthoc & $a<c$ & & & & $a<c$ & \\
\hline
\end{tabular}

$\mathrm{SD}$, standard deviation.

${ }^{*} P<0.05 .{ }^{* *} P<0.01$. Post hoc - Statistically significant difference between groups.

Table 5. Mean and standard deviation of hospital environment constraints according to cancer stage and F-test

\begin{tabular}{|c|c|c|c|c|}
\hline \multirow{2}{*}{$\begin{array}{r}\text { Cancer } \\
\text { stage }\end{array}$} & Program & Space & Tool & Service \\
\hline & Mean \pm SD No. & Mean \pm SD No. & Mean \pm SD No. & Mean \pm SD No \\
\hline 1 & $4.01 \pm 0.58 \quad 48$ & $4.06 \pm 0.56 \quad 48$ & $4.15 \pm 0.6348$ & $4.22 \pm 0.96 \quad 48$ \\
\hline 2 & $4.03 \pm 0.56 \quad 32$ & $4.10 \pm 0.36 \quad 32$ & $4.02 \pm 0.56 \quad 32$ & $4.01 \pm 0.65 \quad 32$ \\
\hline 3 & $4.02 \pm 0.5466$ & $4.01 \pm 0.6466$ & $4.00 \pm 0.3666$ & $4.03 \pm 0.66 \quad 66$ \\
\hline Others & $4.01 \pm 0.5216$ & $4.02 \pm 0.78 \quad 16$ & $4.05 \pm 0.81 \quad 16$ & $4.10 \pm 0.78 \quad 16$ \\
\hline F-value & 0.948 & 1.032 & $4.033^{*}$ & $7.695^{* *}$ \\
\hline Posthoc & & & $c<a$ & $\mathrm{~b}, \mathrm{c}<\mathrm{a}$ \\
\hline
\end{tabular}

$\mathrm{SD}$, standard deviation.

${ }^{*} P<0.05 .{ }^{*} P<0.01$. Post hoc - Statistically significant difference between groups. 
tivity at the initial level, but it is difficult for them to do so because of constraints on exercise tools in the hospital. In the category of "service" $(F=7.695)$, it was higher in the stage $1($ mean $=4.22)$ group than in the stage $2($ mean $=4.01)$ and the stage 3 (mean= 4.03) group (Table 5).

\section{DISCUSSION}

For an analysis of the differences in the self-rated health of patients according to the characteristics of hospitalized cancer patients, this study analyzed differences in self-rated health according to cancer type, stage, and adjunctive treatment and analyzed the recognition of difficulties in physical activities for recovery during hospitalization.

In this study, Today's Health Status of EQ-5D-5L, which is widely used in the study of health-related HRQoL, was used because of the large changes in health status, such as hospitalization period, surgery, and chemotherapy due to the nature of cancer patients. The higher the score, the better the health status. In this study, there was a significant difference in self-rated health according to cancer diagnosis type, cancer stage, and adjunctive treatment. The self-rated health of cancer patients was significantly lower in the gastric cancer $(41.2 \pm 1.23)$ group than in the breast cancer and thyroid cancer group according to cancer diagnosis type, cancer stage, and adjunctive treatment. It was deemed that since the hospitalization period for gastric cancer patients after surgery is longer than for breast cancer patients and thyroid cancer patients and gastric cancer patients tended to evaluate the severity to be higher, their self-rated health was low. For the difference in self-rated heath, it was higher in the order of the stage 3 cancer patients $(23.5 \pm 0.61)<$ stage 2 cancer patients $(35.5 \pm 0.40)$ $<$ other stage $(40.2 \pm 0.42)<$ stage 1 cancer patients $(42.5 \pm 0.45)$. Self-rated health was the lowest in patients treated with both chemotherapy and radiotherapy (40.6 \pm 0.96$)$. In previous studies analyzing differences in self-rated health according to the cancer diagnosis period, the group with a cancer diagnosis period of less than one year showed lower self-rated health than the groups with $2-3$ years, $4-5$ years, and 6 years or more, and the groups of cured patients and patients who finished with treatment showed higher self-rated health (Park and Oh, 2010).

As a result of analysis of the constraints on participation in physical activity during the hospitalization period of cancer patients, the physical and sociocultural constraints among the personal constraints were the highest. In other words, the patients recognized physical activities to be difficult because of physical problems such as fatigue, pain, etc., and a lack of peers or leaders with whom they could participate in physical activities. In addition, most of the hospital environment constraints felt by cancer patients were high, indicating that the physical activity of the patients is restricted and shrinks due to the hospital environment. In particular, for tools and service, stage 1 cancer patients thought it was difficult for them to participate in activities due to the constraint on service and tools. This support the results of a study by Suhonen et al. (2018) that suggests that the lower the self-rated health, the lower the constraints on hospital services and treatment.

There have been revolutionary changes in health care services in recent years. In the linear model in which doctor-treated patients, the roles are organically intertwined, changing into interaction, and the paradigm is changing into a revolutionary collaborative system optimized for individual patients to ensure continuous care as well as disease treatment (Kim et al., 2016). This implies that health care is everything related to the treatment process, and it includes not only treatment by medical staff but also the efforts of the medical staff and the patient to cure the disease after treatment. Physical activity will play a very important role in continuous care. According to previous studies, physical activity has been proved to be effective in preventing cancer and the recurrence of secondary cancers and increasing cancer survival rates (Jeon et al., 2013), improving immunity during chemotherapy (Bigley et al., 2013), and reducing mental stress such as anxiety and depression (Galiano-Castillo et al., 2014). In addition, despite weight loss due to chemotherapy, physical activity may be a positive solution for the problem of increased metabolic risk due to weight gain after treatment (Kim, 2015). However, even if the medical staff recognize the importance of physical activity, it is very rare to practice physical activity during the hospitalization period because of practical safety problems. In fact, patients recognize that the medical staff's advice and education about physical activities other than treatment are inadequate (van Veen et al., 2017), and the recognition of the effect of physical activity and motivation to participate are also determined by the experts after diagnosis of cancer (Eng et al., 2018). In conclusion, personal constraints on the physical activity of cancer patients appear to be due to fatigue and a lack of motivation (Eng et al., 2018), but health care services that influence the patients' motivations is critical to a personalized and continued patient care strategy (Suhonen et al., 2018). In addition, given that patients and their families, the customers of medical services, are emotionally and physically vulnerable, it is very important to take care of consumers continuously with extensive consideration 
(Park et al., 2016).

There is a necessity for further basic studies to analyze the characteristics of individual patients and fundamental causes and to seek ways to practice physical activities so that physical activities to improve the lifestyle of patients and increase the rate of practicing healthy behavior can be applied to the medical field.

\section{CONFLICT OF INTEREST}

No potential conflict of interest relevant to this article was reported.

\section{ACKNOWLEDGMENTS}

This work was supported by the Ministry of Education of the Republic of Korea and the National Research Foundation of Korea (NRF-2016S1A5B6913737).

\section{REFERENCES}

Andersen C, Adamsen L, Moeller T, Midtgaard J, Quist M, Tveteraas A, Rorth $\mathrm{M}$. The effect of a multidimensional exercise programme on symptoms and side-effects in cancer patients undergoing chemotherapy--the use of semi-structured diaries. Eur J Oncol Nurs 2006;10:247262.

Bigley AB, Spielmann G, LaVoy EC, Simpson RJ. Can exercise-related improvements in immunity influence cancer prevention and prognosis in the elderly? Maturitas 2013;76:51-56.

Brooks R. EuroQol: the current state of play. Health Policy 1996;37:53-72.

Chang IY, Yi ES. The influence of environmental constraints within hospitals on physical activity level of cancer patients. J Exerc Rehabil 2018; 14:382-386.

Eng L, Pringle D, Su J, Shen X, Mahler M, Niu C, Charow R, Tiessen K, Lam C, Halytskyy O, Naik H, Hon H, Irwin M, Pat V, Gonos C, Chan C, Villeneuve J, Harland L, Shani RM, Brown MC, Selby P, Howell D, Xu W, Liu G, Alibhai SMH, Jones JM. Patterns, perceptions, and perceived barriers to physical activity in adult cancer survivors. Support Care Cancer 2018;26:3755-3763.

Galiano-Castillo N, Ariza-García A, Cantarero-Villanueva I, FernándezLao C, Díaz-Rodríguez L, Arroyo-Morales M. Depressed mood in breast cancer survivors: associations with physical activity, cancer-related fatigue, quality of life, and fitness level. Eur J Oncol Nurs 2014; 18:206-210.

Hennessy EM, Stevinson C, Fox KR. Preliminary study of the lived experience of exercise for cancer survivors. Eur J Oncol Nurs 2005;9:155-
166.

Hinz A, Krauss O, Hauss JP, Höckel M, Kortmann RD, Stolzenburg JU, Schwarz R. Anxiety and depression in cancer patients compared with the general population. Eur J Cancer Care (Engl) 2010;19:522-529.

Jacobsen R, Samsanaviciene J, Liuabarskiene Z, Sciupokas A. Barriers to pain management among Lithuanian cancer patients. Pain Pract 2010; 10:145-157.

Jeon J, Sato K, Niedzwiecki D, Ye X, Saltz LB, Mayer RJ, Mowat RB, Whittom R, Hantel A, Benson A, Wigler DS, Atienza D, Messino M, Kindler H, Venook A, Fuchs CS, Meyerhardt JA. Impact of physical activity after cancer diagnosis on survival in patients with recurrent colon cancer: findings from CALGB 89803/Alliance. Clin Colorectal Cancer 2013;12:233-238

Kim NH. Cancer survivors at risk of metabolic disorder. Korean J Obes 2015;24:197-198.

Kim RH, Gaukler GM, Lee CW. Improving healthcare quality: a technological and managerial innovation perspective. Technol Forecast Soc Change 2016;113(Part B):373-378.

Korea Centers for Disease Control and Prevention. Disability stats [Internet]. Cheongju (Korea): Korea Centers for Disease Control and Prevention; 2017 Dec [cited 2018 May 10]. Available from: http://www.nih.go. kr/NIH_NEW/contents/NihKrContentView.jsp?cid=64701\&menuIds= HOME005-MNU20.

Li CI, Daling JR, Porter PL, Tang MT, Malone KE. Relationship between potentially modifiable lifestyle factors and risk of second primary contralateral breast cancer among women diagnosed with estrogen receptor-positive invasive breast cancer. J Clin Oncol 2009;27:5312-5318.

Midtgaard J, Baadsgaard MT, Møller T, Rasmussen B, Quist M, Andersen C, Rørth M, Adamsen L. Self-reported physical activity behaviour; exercise motivation and information among Danish adult cancer patients undergoing chemotherapy. Eur J Oncol Nurs 2009;13:116-121.

Ministry of Health and Welfare. Disability stats [Internet]. Deajeon (Korea): Ministry of Health and Welfare; c2018 [cited 2018 May 10]. Available from: http://www.index.go.kr/potal/main/EachDtlPageDetail.do? idx_cd=2768.

Park GW, Kim Y, Park K, Agarwal A. Patient-centric quality assessment framework for healthcare services. Technol Forecast Soc Chang 2016; 113(Part B):468-474.

Park JS, Oh YJ. An analysis of cancer symptoms, perceived health status, and given nursing services for community dwelling cancer patients who are registered in a public health center. J Korean Oncol Nurs 2010; 10:48-58

Parsaie FA, Golchin M, Asvadi I. A comparison of nurse and patient perceptions of chemotherapy treatment stressors. Cancer Nurs 2000;23: 371-374. 
Pinto BM, Trunzo JJ, Reiss P, Shiu SY. Exercise participation after diagnosis of breast cancer: trends and effects on mood and quality of life. Psychooncology 2002;11:389-400.

Shrestha P, Ghimire L. A review about the effect of life style modification on diabetes and quality of life. Glob J Health Sci 2012;4:185-190.

Suhonen R, Stolt M, Berg A, Katajisto J, Lemonidou C, Patiraki E, Sjövall K, Charalambous A. Cancer patients' perceptions of quality-of-care attributes-associations with age, perceived health status, gender and education. J Clin Nurs 2018;27:306-316.

Tajima R, Kondo M, Kai H, Saito C, Okada M, Takahashi H, Doi M, Tsuruo- ka S, Yamagata K. Measurement of health-related quality of life in patients with chronic kidney disease in Japan with EuroQol (EQ-5D). Clin Exp Nephrol 2010;14:340-348.

van Veen MR, Hoedjes M, Versteegen JJ, van de Meulengraaf-Wilhelm N, Kampman E, Beijer S. Improving oncology nurses' knowledge about nutrition and physical activity for cancer survivors. Oncol Nurs Forum 2017;44:488-496.

Young-McCaughan S, Arzola SM. Exercise intervention research for patients with cancer on treatment. Semin Oncol Nurs 2007;23:264-274. 